University of South Carolina

Scholar Commons

8-10-2010

\title{
Guest Induced Transformations of Assembled Pyridyl Bis-Urea Macrocycles
}

\author{
Kinkini Roy \\ University of South Carolina - Columbia \\ Chun Wang \\ University of South Carolina - Columbia \\ Mark D. Smith \\ University of South Carolina - Columbia, mdsmith3@mailbox.sc.edu \\ Mahender B. Dewal \\ University of South Carolina - Columbia \\ Arief C. Wibowo \\ University of South Carolina - Columbia
}

See next page for additional authors

Follow this and additional works at: https://scholarcommons.sc.edu/chem_facpub

Part of the Chemistry Commons

\section{Publication Info \\ Published in Chemical Communications, Volume 47, Issue 1, 2010, pages 277-279. \\ (C) Chemical Communications 2010, Royal Society of Chemistry.}

This Article is brought to you by the Chemistry and Biochemistry, Department of at Scholar Commons. It has been accepted for inclusion in Faculty Publications by an authorized administrator of Scholar Commons. For more information, please contact digres@mailbox.sc.edu. 


\section{Author(s)}

Kinkini Roy, Chun Wang, Mark D. Smith, Mahender B. Dewal, Arief C. Wibowo, Julius C. Brown, Shugo Ma, and Linda S. Shimizu 


\title{
Guest induced transformations of assembled pyridyl bis-urea macrocycles $\dagger \ddagger$
}

\author{
Kinkini Roy, ${ }^{a}$ Chun Wang, ${ }^{a}$ Mark D. Smith, ${ }^{a}$ Mahender B. Dewal, ${ }^{a}$ Arief C. Wibowo, ${ }^{a}$ \\ Julius C. Brown, ${ }^{a}$ Shuguo $\mathrm{Ma}^{b}$ and Linda S. Shimizu*a
}

Received 18th June 2010, Accepted 16th July 2010

DOI: $10.1039 / \mathrm{c0cc01952f}$

Pyridine macrocycles with no cavities assembled into close packed columns yet absorbed guests including hydrogen, carbon dioxide, and iodine.

Many different approaches have been used to design materials with open channels that display permanent porosity. ${ }^{1}$ Recent examples indicate that a permanent pore or channel is not necessarily a requirement for the absorption of gases. ${ }^{2}$ Dynamic structural changes in coordination polymers induced new channels into which guest molecules were incorporated. ${ }^{3}$ Atwood et al. recently demonstrated that non-porous organic solids could expand by gas induced transformations. ${ }^{4}$ In this manuscript, we report a pyridyl bis-urea host (1, Fig. 1) that assembled into columns with high fidelity. Close packing of these columns gives a high density structure with no obvious channels. Co-crystallization of host $\mathbf{1}$ with trifluoroethanol (TFE)

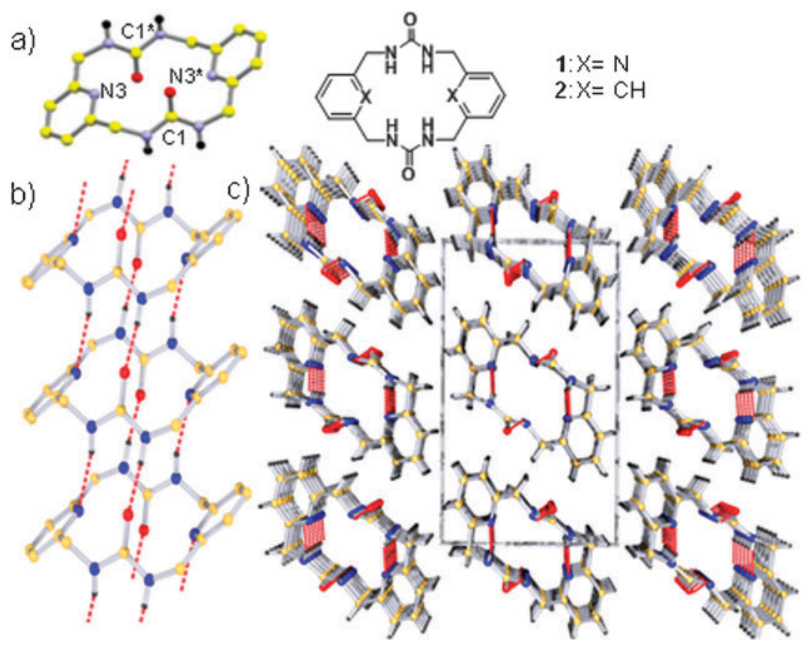

Fig. 1 Macrocyclic bis-ureas 1 and 2: (a) structure of host 1 with intramolecular distances from $\mathrm{C} 1$ to $\mathrm{C} 1^{*}=4.645 \AA$ and $\mathrm{N} 3$ to $\mathrm{N} 3 *=$ $5.066 \AA$; (b) view along a single column of host 1 illustrating the hydrogen bonding pattern; (c) view depicting the packing of the columns.

${ }^{a}$ Department of Chemistry and Biochemistry,

University of South Carolina, Columbia, South Carolina, USA.

E-mail: shimizul@chem.sc.edu; Fax: +1803-777-9521;

Tel: +1 803-777-2066

${ }^{b}$ College of Engineering and Computing,

University of South Carolina, Columbia, South Carolina, USA

$\dagger$ Electronic supplementary information (ESI) available: Experimental details including the synthesis and characterization of host 1 and its inclusion complexes and crystallographic analysis. CCDC reference numbers 781839-781840. For ESI and crystallographic data in CIF or other electronic format see DOI: $10.1039 / \mathrm{c} 0 \mathrm{cc} 01952 \mathrm{f}$

$\ddagger$ This article is part of the 'Emerging Investigators' themed issue for ChemComm. formed a crystalline inclusion complex host 1.TFE with TFE separating the columns of assembled bis-ureas. Heating induced desorption of the TFE regenerated the initial host 1 extended structure. While there are examples of crystals that can expand to absorb guests, we were surprised to observe type I gas adsorption isotherms with $\mathrm{H}_{2}$ and $\mathrm{CO}_{2}$, which usually indicate permanent channels. Furthermore, these crystals displayed reversible absorption of iodine to afford a stable crystalline host $\mathbf{1} \cdot \mathrm{I}_{2}$ complex. Closer analysis suggested guest induced transformations that converted a higher density 'guest free' form of bis-urea host 1 to a lower density form. We investigated these structures by X-ray diffraction, X-ray photoelectron spectroscopy (XPS) and UV-vis spectroscopy. These studies suggest that the organic solid state can be dynamic and can expand to encapsulate guests.

We have previously shown that ureas, preorganized within rigid frameworks, guided columnar assembly through the strong 3-centered urea hydrogen bonding motif. ${ }^{5}$ Macrocycles with sizeable cavities afford open columnar channels that are accessible to gases and guests; however, we expected macrocycles that lacked a cavity to be nonporous. For example, previously reported $m$-xylene $\mathbf{2}$ assembled into columns through typical 3-centered urea interactions, ${ }^{6}$ but the inward facing aryl hydrogens were nearly within van der Waals contact. We recently synthesized pyridine $\mathbf{1}$, which contains basic interior nitrogens with no central cavity. Macrocycle 1 was synthesized in two steps from 2,6-dibromomethylpyridine and triazinanone $(\mathrm{ESI} \dagger)$. Colorless crystals of $\mathbf{1}$ were obtained by vapor diffusion of methanol into a DMSO solution of $\mathbf{1}$ $(10 \mathrm{mg} / 2 \mathrm{~mL})$. X-Ray analysis $\S$ revealed the expected bis-urea macrocycle (Fig. 1a). Accounting for van der Waals radii, the interior of the macrocycle was $\sim 1.1 \times 1.8 \AA$ (Fig. 1a). In comparison, gases used to measure porosity have kinetic diameters of $2.9\left(\mathrm{H}_{2}\right)$ to $3.6 \AA\left(\mathrm{N}_{2}\right){ }^{7}$ The individual macrocycles 1 were connected into columns by hydrogen bonds between the urea NH's and two different acceptors: the urea carbonyl oxygen and the pyridine nitrogen (Fig. 1b). The carbonyl oxygen formed slightly shorter interactions with an $\mathrm{N}-\mathrm{O}$ distance of 2.904(2) $\AA$ vs. the pyridine N, which displayed an N-N distance of 3.082(2) $\AA$. This hydrogen bonding motif gave a repeat distance of $\sim 4.7 \AA$, similar to the typical 3-centered urea motif. ${ }^{6}$ The chains of hydrogen bonds run along the crystallographic $b$ axis and the columns are densely packed with no obvious channels (Fig. 1c).

Host 1 also crystallized through the vapor diffusion of TFE into a DMSO solution of $1(10 \mathrm{mg} / 2 \mathrm{~mL})$ to afford a 1.TFE complex. This structure showed columns with similar distances from the urea $\mathrm{NHs}$ to the heteroatoms 


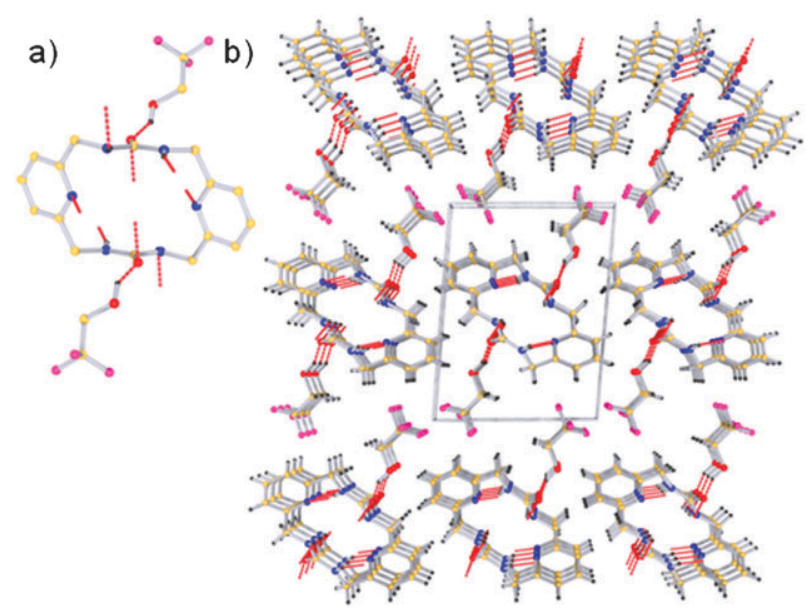

Fig. 2 Views from the X-ray structure of host 1.TFE: (a) the hydrogen bonding environment of a single macrocycle was nearly identical to the solvent-free structure except for a TFE molecule that was hydrogen bonded to the carbonyl; (b) view depicting the packing of the columns.

$(\mathrm{N}-\mathrm{O}=2.928(4) \AA, \mathrm{N}-\mathrm{N}=3.038(4) \AA)$. The important difference between the two structures was the hydrogen bonding interaction between the alcohol of TFE and urea carbonyl oxygen (Fig. 2a). The TFE forms an interstitial layer between a layer of columns (Fig. 2b). There is a change in symmetry between the solvent free and solvent complex crystals from monoclinic $z=2$ to triclinic $z=1$. To compare their volumes, we divided the solvent free cell volume by 2 . The host 1.TFE had a larger volume $\left(563.69 \AA^{3}\right) v s$. host $1\left(364.39 \AA^{3}\right)$, which reflected the space occupied by solvent.

These crystalline solids were ground to powders and examined by powder X-ray diffraction. In each case, the observed PXRD patterns closely matched the theoretical PXRD pattern calculated from the respective single crystal structures, indicating that these bulk powders had the same overall structure as their crystalline solids (ESI $\dagger$ ). The solvent was removed from host 1.TFE powder by heating and the powder re-examined by PXRD (Fig. 3a). The peak positions and intensities were similar to the original host $\mathbf{1}$ structure.

Host $\mathbf{1}$ and $\mathbf{2}$ were not expected to display permanent porosity and were examined as controls for gas adsorption. Surprisingly, host $\mathbf{1}$ crystals displayed a type I gas adsorption isotherm with $\mathrm{CO}_{2}(\mathrm{~g})$ at $273 \mathrm{~K}$ consistent with microporous materials (Fig. 3b) ${ }^{8}$ as did host 2 (ESI $\dagger$ ). The BrunauerEmmett-Teller method was applied to the $\mathrm{CO}_{2}$ isotherm for host 1 at $P / P_{0}$ between 0.016 and 0.028 . The calculated surface

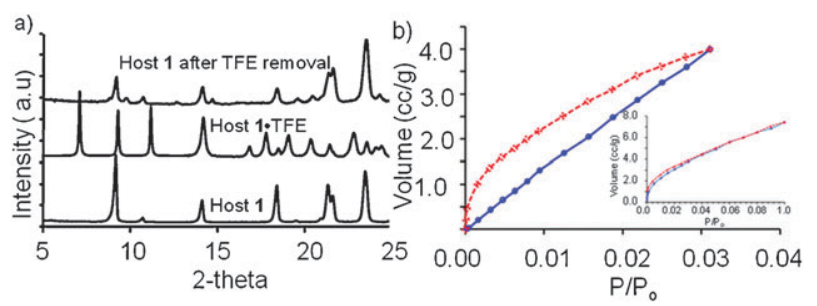

Fig. 3 (a) Comparison of PXRD patterns for host 1 (bottom), host 1.TFE (middle) and host 1.TFE after TFE removal (top); (b) carbon dioxide adsorption isotherms at $273 \mathrm{~K}$ for host $\mathbf{1}$ (adsorption in blue, desorption in red) and hydrogen adsorption isotherms at $273 \mathrm{~K}$ for host 1 (inset). area of $190 \mathrm{M}^{2} \mathrm{~g}^{-1}$ corresponds to a total pore volume of $3.852 \times 10^{-3} \mathrm{~cm}^{3} \mathrm{~g}^{-1}$ for pores smaller than $6.3 \AA$ in diameter. Host 1 also displayed a similar type 1 adsorption isotherm with $\mathrm{H}_{2}$ (g) (Fig. 3b, inset). Both these gases have kinetic diameters that were larger than any void in the hosts. Thus, our hypothesis is that these hosts undergo gas induced transformations where the columns are pushed apart to accept the gas as observed in the host 1.TFE inclusion complex.

The ability of host $\mathbf{1}$ to form inclusion complexes with TFE through hydrogen bonding interactions with the unsatisfied oxygen lone pair, led us to the consider other guests whose structures would be easier to monitor. In host $\mathbf{2}$, the lone pairs were occupied in the 3-centered urea hydrogen bonds, thus this compound was tested as a control. We next investigated if hosts 1 and $\mathbf{2}$ absorbed $I_{2}$, which was well-known to form charge transfer complexes with pyridine. ${ }^{9}$ The colorless crystals of hosts 1 and $\mathbf{2}$ were exposed to iodine vapors in a sealed container for 1-9 days. The vapor loading of iodine in host $\mathbf{1}$ to afford red crystals was kinetically slow, requiring $\sim 7$ days to reach equilibrium. The desorption of iodine from these crystals was followed by thermogravimetric analysis (TGA). A one step desorption with $19.18 \%$ weight loss was observed between $60{ }^{\circ} \mathrm{C}$ to $140{ }^{\circ} \mathrm{C}$ from the host $\mathbf{1} \cdot \mathrm{I}_{2}$ complex (Fig. $4 \mathrm{a}$ ). Assuming that this weight loss corresponded to $\mathrm{I}_{2}$, we calculated a $3: 1$ host : guest ratio in the host $\mathbf{1} \cdot \mathrm{I}_{2}$ complex. No weight loss was observed for the iodine treated host 2 samples, indicating that $\mathrm{I}_{2}$ was not absorbed.

Iodine could also be loaded reproducibly from an ethanolic solution and reached a saturation absorption of $280( \pm 20) \mathrm{mg}$ $\mathrm{I}_{2}$ per gram of 1 . This corresponds to the same $3: 1$ binding ratio $\left(1: \mathrm{I}_{2}\right)$. To further investigate this binding phenomenon, host $1(55 \mathrm{mg})$ was loaded in a capillary and equilibrated with iodine vapor for 7 days. We monitored the daily increase in volume by measuring the change in length. After 7 days a $14 \%$ increase in volume was observed (ESI $\dagger$ ). The expansion of 1 was presumably due to the formation of a clathrate (host $\mathbf{1} \cdot \mathrm{I}_{2}$ ).

Powder X-ray diffraction (PXRD) was used to compare the structure of the host $\mathbf{1}$ and its $\mathrm{I}_{2}$ complex. The host $\mathbf{1} \cdot \mathrm{I}_{2}$ complex exhibited a PXRD pattern (Fig. 4b top) that was different from the free host. We observed a shift in the diffraction peak positions towards smaller $2 \theta$ values for the lower angle (102) peak from $14.1^{\circ}$ to $12.55^{\circ}$ and the (202) peak $\left(21.3^{\circ}\right.$ to $\left.19.6^{\circ}\right)$. These changes suggested that the cell was expanding in the $a-c$ direction as expected for iodine bound between the columns. The iodine was removed by heating and the PXRD positions and intensities mirrored those of the initial host 1 structure (ESI $\dagger$ ).

We next investigated the nature of the bound iodine species. The empty host $\mathbf{1}$ exhibited an absorbance maximum at

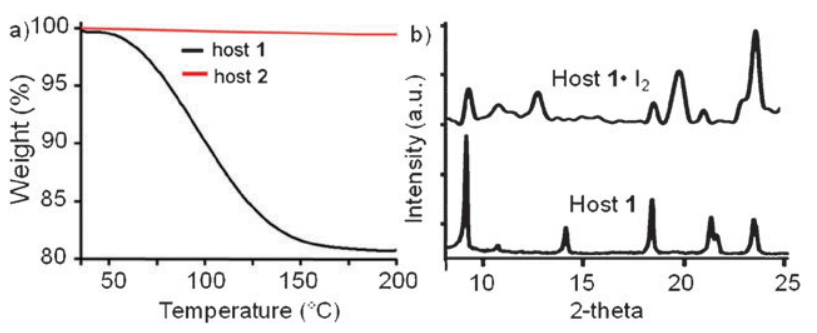

Fig. 4 (a) TGA desorption curves for the iodine treated host 1 and host 2; (b) comparison of the PXRD patterns of host $\mathbf{1}$ and host $\mathbf{1} \cdot \mathrm{I}_{2}$. 


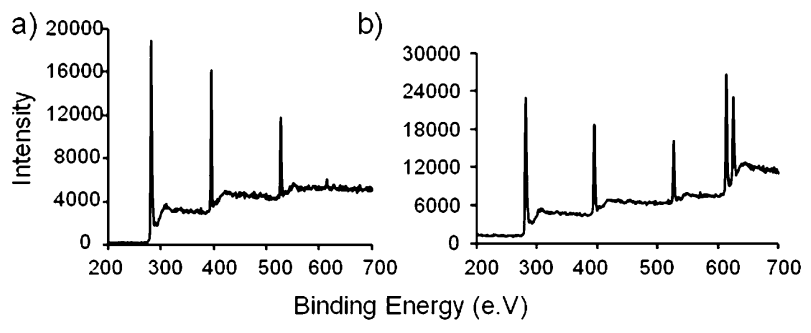

Fig. 5 Comparison of XPS survey scans: (a) host 1; (b) host $\mathbf{1} \cdot \mathrm{I}_{2}$ complex.

$\lambda_{\max } 278 \mathrm{~nm}$ that was blue shifted to $262 \mathrm{~nm}$ in the $\mathbf{1} \cdot \mathrm{I}_{2}$ complex, indicative of a charge transfer (CT) complex. ${ }^{9,10}$ Two additional absorbance bands were observed at $\lambda_{\max } 286$ and $355 \mathrm{~nm}$, which were characteristic of iodine charge transfer bands $($ ESI $\dagger) .{ }^{11}$

Solid-state IR was used to compare host $\mathbf{1}, \mathbf{2}$, and the host $\mathbf{1} \cdot \mathrm{I}_{2}$ complex. Host $\mathbf{2}$ has typical urea hydrogen bonds with two NH stretches at 3365 and $3306 \mathrm{~cm}^{-1}$. In the host $\mathbf{1}$ structure, the NH's were paired with two separate acceptors, which was reflected in the IR by the shift of the NH stretch to shorter wavenumbers (3328 and $\left.3269 \mathrm{~cm}^{-1}\right) .{ }^{12}$ Little change was observed in the $\mathrm{NH}$ region upon uptake of iodine. Only one NH stretch shifted from 3326 to $3321 \mathrm{~cm}^{-1}$. This may signal a slight strengthening of the pyridine $\mathrm{NH}$ hydrogen bond. No change was observed in the carbonyl band $\left(1658 \mathrm{~cm}^{-1}\right)$. We observed small perturbations in the pyridine ring in the $\mathbf{1} \cdot \mathrm{I}_{2}$ complex. The $\mathrm{C}=\mathrm{N}$ stretch moved to higher frequency (from 1568 to $1572 \mathrm{~cm}^{-1}$ ) and the in plane pyridine $\mathrm{H}$-deformation shifted from $1106 \mathrm{~cm}^{-1}$ to $1130 \mathrm{~cm}^{-1} .13$

The electronic structure of empty host 1 (Fig. 5a) and the host $\mathbf{1} \cdot \mathrm{I}_{2}$ complex (Fig. 5 b) was further probed by XPS. ${ }^{14}$ Two intense peaks shown in Fig. $5 \mathrm{~b}$ around $620 \mathrm{eV}$ were I $3 \mathrm{~d}$ core level XPS lines. No other iodine peaks were observed in this region suggesting that only one type of iodine was present. ${ }^{15}$ The I MNN Auger line and I3d XPS spectrum for NaI reference were measured and the Auger parameter obtained. ${ }^{16}$ The $\mathbf{1} \cdot \mathrm{I}_{2}$ sample showed a similar Auger parameter, which suggested that iodine acquired a partial negative charge upon complex formation. ${ }^{17}$ The XPS spectrum of N1s for host $\mathbf{1} \cdot \mathrm{I}_{2}$ showed that the binding energy of N1s was higher than that for host $\mathbf{1}$, suggesting that the pyridine nitrogen was partially positive in host $\mathbf{1} \cdot \mathrm{I}_{2}(\mathrm{ESI} \dagger) .{ }^{17}$ Taken together, these experiments support the formation of a pyridine-iodine CT complex that does not significantly alter the hydrogen bonding motif of the individual columns.

In summary, we report a pyridine functionalized bis-urea macrocycles that self-assembled into columnar structures lacking pores. Despite the lack of pores, this host was able to complex guests including TFE and $\mathrm{I}_{2}$ that can interact relatively strongly with the host. More surprising was the ability of this close packed organic host to absorb weakly interacting guests including $\mathrm{H}_{2}(\mathrm{~g})$ and $\mathrm{CO}_{2}(\mathrm{~g})$. These results highlight the potential use of organic crystals as sorbants. We are now investigating the binding of other guests within this new host as well as within larger pyridyl bis-urea macrocycles.

The authors acknowledge support for this work from the NSF (CHE-0718171, CHE-1012298) and from the University of South Carolina, Office of Research and Health Sciences.

\section{Notes and references}

$\S$ Crystallographic data for $1: \mathrm{C}_{16} \mathrm{H}_{18} \mathrm{~N}_{6} \mathrm{O}_{2}, M=326.36$, colorless block crystal, $0.24 \times 0.22 \times 0.10 \mathrm{~mm}^{3}, T=150 \mathrm{~K}$. Monoclinic, space group $P 2_{1} / c, a=9.5207(5), b=4.6948(3), c=16.3045(9) \AA$, $\beta=90.201(1)^{\circ}, U=728.77(7) \AA^{3}, Z=2, D_{\mathrm{c}}=1.487 \mathrm{Mg} \mathrm{m}^{-3}$, $F(000)=344$. Bruker SMART APEX CCD-based diffractometer system, $\lambda=0.71073 \AA(\mathrm{Mo}-\mathrm{K} \alpha), \theta_{\max }=26.37^{\circ}, 8648$ reflections measured, 1489 unique, 1214 with $I>2 \sigma(I), R_{\text {int }}=0.0502$. Final $R$-values: $R_{1}(F, I>2 \sigma(I))=0.0352 ; \mathrm{w} R_{2}\left(F^{2}\right.$, all data $)=0.0875$. For 1.TFE: $\mathrm{C}_{16} \mathrm{H}_{18} \mathrm{~N}_{6} \mathrm{O}_{2} \cdot 2\left(\mathrm{CF}_{3} \mathrm{CH}_{2} \mathrm{OH}\right) \quad M=526.45$, colorless block crystal, $0.60 \times 0.06 \times 0.04 \mathrm{~mm}^{3}, T=150 \mathrm{~K}$. Triclinic, space group $P \overline{1}, a=4.6955(12), b=9.632(3), c=12.775(3) \AA, \alpha=93.970(5)^{\circ}$, $\beta=100.219(5)^{\circ}, \gamma=95.594(5)^{\circ}, U=563.7(2) \AA^{3}, Z=1, D_{\mathrm{c}}=$ $1.551 \mathrm{Mg} \mathrm{m}^{-3}, F(000)=272$. Bruker SMART APEX CCD-based diffractometer system, $\lambda=0.71073 \AA(\mathrm{Mo}-\mathrm{K} \alpha), \theta_{\max }=24.94^{\circ}, 5796$ reflections measured, 1970 unique, 1372 with $I>2 \sigma(I), R_{\text {int }}=0.0583$. Final $R$-values: $R_{1}(F, I>2 \sigma(I))=0.0684 ; \mathrm{w} R_{2}\left(F^{2}\right.$, all data $)=$ 0.1908 .

1 M. E. Davis, Nature, 2002, 417, 813; O. M. Yaghi, M. O'Keeffe, N. W. Ockwig, H. K. Chae, M. Eddaoudi and J. Kim, Nature, 2003, 423, 705.

2 S. J. Dalgarno, P. K. Thallapally, L. J. Barbour and J. L. Atwood, Chem. Soc. Rev., 2007, 36, 236.

3 C.-L. Chen, A. M. Goforth, M. D. Smith, C.-Y. Su and H.-C. zur Loye, Angew Chem., Int. Ed., 2005, 44, 2; R. Kitaura, K. Seki, G. Akiyama and S. Kitagawa, Angew. Chem., Int. Ed., 2003, 42, 428; K. Biradha, Y. Hongo and M. Fujita, Angew. Chem., Int. Ed. 2002, 41, 3395; S. A. Dalrymple and G. K. H. Shimizu, Chem. Commun., 2006, 956; A. Kondo, H. Noguchi, S. Ohnishi, H. Kajiro, A. Tohdoh, Y. Hattori, W.-C. Xu, H. Tanaka, H. Kanoh and K. Kaneko, Nano Lett., 2006, 6, 2581; C.-L. Chen and A. M. Beatty, J. Am. Chem. Soc., 2008, 130, 17222.

4 J. L. Atwood, L. J. Barbour, A. Jerga and B. L. Schottel, Science, 2002, 298, 1000; P. K. Thallapally, L. Dobrzanska, T. R. Gingrich, T. B. Wirsig, L. J. Barbour and J. L. Atwood, Angew. Chem., Int. Ed., 2006, 45, 6506; P. K. Thallapally, B. P. McGrail, S. J. Dalgarno, H. R. Schaef, J. Tian and J. L. Atwood, Nat. Mater., 2008, 7, 146.

5 M. B. Dewal, Y. Xu, J. Yang, F. Mohammed, M. D. Smith and L. S. Shimizu, Chem. Commun., 2008, 3909; L. S. Shimizu, A. D. Hughes, M. D. Smith, M. J. Davis, P. Zhang, H.-C. zur Loye and K. D. Shimizu, J. Am. Chem. Soc., 2003, 125, 14972.

6 L. S. Shimizu, M. D. Smith, A. D. Hughes and K. D. Shimizu, Chem. Commun., 2001, 1592.

7 D. W. Breck, Zeolite Molecular Sieves: Structure, Chemistry, and Use, 1974, p. 752.

8 K. S. W. Sing, D. H. Everett, R. A. W. Haul, L. Moscou, R. A. Pierotti, J. Rouquerol and T. Siemieniewska, Pure Appl. Chem., 1985, 57, 603.

9 C. Reid and R. S. Mulliken, J. Am. Chem. Soc., 1954, 76, 3869; N. Rao, S. Rao, G. Babu and D. Ziessow, Spectrochim. Acta, Part A, 1990, 46, 1107.

10 C. Hayakawa, K. Urita, T. Ohba, H. Kanoh and K. Kaneko, Langmuir, 2009, 25, 1795; C. Reid and R. S. Mulliken, J. Am. Chem. Soc., 1954, 76, 3869.

11 De Laurentis, V. Losacco, M. A. Milillo and A. Zarrilli, Boll. Chim. Farm., 2001, 140, 15.

12 R. M. Silverstein, F. X. Webster and D. J. Kiemle, in Spectroscopic Identification of Organic Compounds, John Wiley \& Sons, Inc, Hoboken, NJ, 7th edn., 2005, pp. 72-126, ch. 2.

13 F. M. Abdel Kerim and F. A. Fotouh, Appl. Spectrosc., 1976, 30, 200.

14 C. M. Whelan, F. Cecchet, R. Baxter, F. Zerbetto, G. J. Clarkson, D. A. Leigh and P. Rudolf, J. Phys. Chem. B, 2002, 106, 8746.

15 L. Grigorian, K. A. Williams, S. Fang, G. U. Sumanasekera, A. L. Loper, E. C. Dickey, S. J. Pennycook and P. C. Eklund, Phys. Rev. Lett., 1998, 80, 5560; Z. He, X. Xu, S. Song, L. Xie, J. Tu, J. Chen and B. Yan, J. Phys. Chem. C, 2008, 112, 16431.

16 K. R. Kissell, K. B. Hartman, P. A. W. Van der Heide and L. J. Wilson, J. Phys. Chem. B, 2006, 110, 17425.

17 W. Wu, L. Liu, Y. Li, Z. Guo, L. Dai and D. Zhu, Fullerenes Nanotubes Carbon Nanostruct., 2003, 11, 89; S. Ye, A. K. Vijh and L. H. Dao, J. Electrochem. Soc., 1997, 144, 90. 